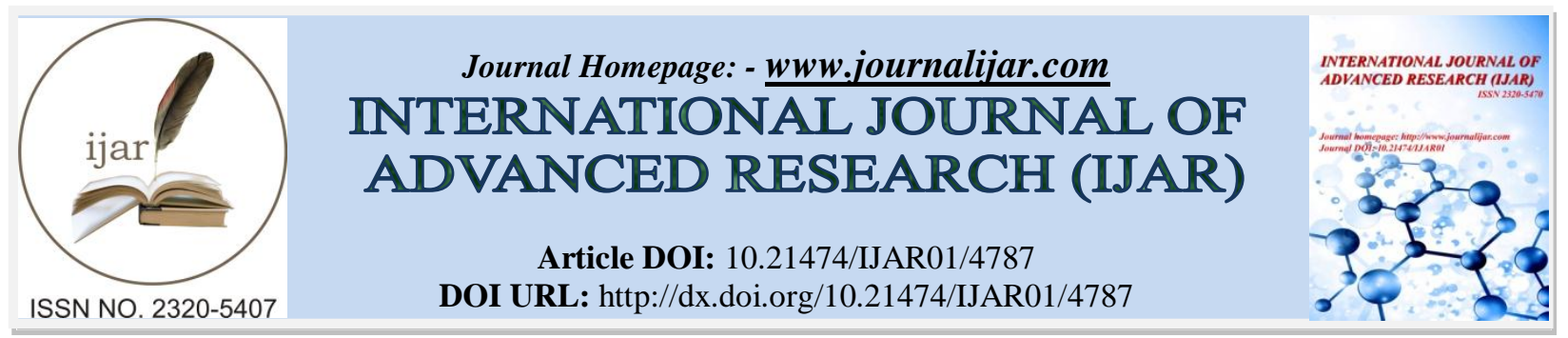

RESEARCH ARTICLE

\title{
ENCAPSULATION OF VENLAFAXINE HCL IN TO POLY-E-CAPROLACTONE MICROSPHERES BY W/O/W AMD W/O/O EMULSION SOLVENT EVAPORATION TECHNIQUE AND COMPARISON FOR ITS CONTROLLED RELEASE PROPERTIES.
}

\author{
"Manabendra Rabha' ${ }^{1}$ and Dr. Bipul Nath' \\ 1. M. Pharm., Department of Pharmaceutics, Girijananda Institute of Pharmaceutical Sciences, Azara, Guwahati, \\ Assam-781017, India. \\ 2. Girijananda Chowdhury Institute of Pharmaceutical Science, Azara, Guwahati-781017, India.
}

\section{Manuscript Info}

\section{Manuscript History}

Received: 8 May 2017

Final Accepted: 10 June 2017

Published: July 2017

Key words:-

Microencapsulation, Venlafaxine,

double emulsification, controlled drug

delivery system, poly-e-caprolactone.

\section{Abstract}

Objective: The objective of the proposed work was to investigate the method for the efficient encapsulation of highly water soluble venlafaxine hydrochloride into poly-e-caprolactone microspheres by water-in-oil-in-oil and water-in-oil-in water double emulsification technique and comparison for its controlled release properties.

Method: The Venlafaxine loaded microspheres are prepared by water-in-oil-in-oil (w/o/w) and water-in-oil-in water (w/o/o) double emulsification technique. The compatibility study of drug with polymer was performed by Differential scanning caloriemetry (DSC) and Fourier transform infrared spectroscopy (FT-IR). The prepared microspheres are studied for their particle size, drug entrapment efficiency. The microspheres are characterised by SEM and in-vitro release of Venlafaxine was studied in phosphate buffer $\mathrm{pH} 1.2$ for 12 hours and further studied for kinetic modeling.

Result: The precentage yield of Venlafaxine loaded microspheres of all the formulations were found better by w/o/w method( $92.21 \%$ for $\mathrm{F}$ $3)$. The particle size was found in a range of 130-135 $\mu \mathrm{m}$ and 120-125 $\mu \mathrm{m}$ for both $\mathrm{W} / \mathrm{O} / \mathrm{W}$ and $\mathrm{W} / \mathrm{O} / \mathrm{O}$ formulations. The entrapment efficiency was found in $\mathrm{F} 5$ formulation prepared by W/O/O method. While the in-vitro release of Venlafaxine showed a drug release below $60 \%$ after $12 \mathrm{~h}$ of study whereas the marketed formulation released above $90 \%$ within $6 \mathrm{~h}$ and the mechanism was found to be fickian type.

Conclusion: The prepared poly- $\varepsilon$-caprolactone microsphere is capable of delivering Venlafaxine $\mathrm{HCl}$ over prolonged periods, making it a potential candidate for controlled drug delivery.

Copy Right, IJAR, 2017,. All rights reserved.

\section{Introduction:-}

Micro-encapsulation or micro-particulate delivery system has emerged as one of the best controlled drug delivery system, which delivers the drugs in a controlled rate over a period of time(Raval et al., 2014). The use of controlledrelease formulations to deliver drugs to the site of action has is gaining interest. In order to develop a controlled drug delivery system, the micro-particulate system is prepared having a polymer whether natural or synthetic judiciously 
combined enclosed with a drug in such a way that the active agent is released from the material in a pre-designed manner. These particulate based systems for the delivery of drugs are believed to enhance bioavailability, predictable therapeutic response, greater efficacy and safety and controlled and prolonged drug release profile. It provides effective treatment at the site of action at much lower doses. They are especially important in the case of poor drug distribution at the site of infection due to limited blood circulation to the surrounding skeletal tissue(Di Silvio and Bonfield, 1999; Paul and Sharma, 2003). The theory that polymers could be used as drug carriers to provide the controlled release of drug(s) is now well established. Biodegradable polymers are extensively employed in controlled-release drug delivery devices because of their abundant source, lack of toxicity, high tissue compatibility and they are the possible means of delivering drugs by several routes of administration. Among synthetic materials, biodegradable polyesters, approved by the Food and Drug Administration (FDA) for human use, are rapidly gaining recognition. Poly(e-caprolactone) (PCL) is a well-known hydrophobic, synthetic polyester with excellent tissue compatibility, biodegradability and existing regulatory approval(Hombreiro Pérez et al., 2000; Lionzo et al., 2007). Degradation of PCL in comparison to poly (lactide-co-glycolide) (PLGA) and other polymers is slow, making it suitable for long-term delivery extending over a period of more than 1 year. This has led to its application in the preparation of different delivery systems in the form of microspheres, nanoparticles and implants.

Venlafaxine $\mathrm{HCl}$ is a new generation antidepressant serotonin / noradrenalin reuptake inhibitor drug showing effective anti-depressant properties. It has a short oral bioavailability of $45 \%$ and biological half-life of $4-5$ hours. The total daily dose of Venlafaxine is $225-375 \mathrm{mg} / \mathrm{day}$ in moderate and severe depressive disorder. So, frequent administration is necessary to maintain its therapeutic concentration. This necessitates of frequent administration of large doses ( $75 \mathrm{mg}$ every 4 to $5 \mathrm{~h}$ three times daily or four times daily) to maintain therapeutic drug level (https://dailymed.nlm.nih.gov/dailymed/archives/fdaDrugInfo.cfm?archiveid=9595, 12/2008).

The side effects of Venlafaxine are dose dependent and a reduction of the total administered dose reduces the severity of the toxicity. Thus the short half-life of $4 \mathrm{~h}$ and frequent dosing of large doses due to low oral bioavailability makes Venlafaxine a good candidate for microencapsulation. Hence, there is a need for developing sustained release dosage form of Venlafaxine that maintains improved bioavailability and therapeutic plasma drug concentration for long period compared to conventional dosage forms. Microencapsulation may improve the absorption of a drug and maintain its plasma concentration within the therapeutic index. Ibrahim et al, 2016 reported about formulation of Venlafaxine for once daily administration using polymeric material hybrids. The developed formulation of PLA/ Eudragit at 1:1 ratio sustained the drug release up to $24 \mathrm{~h}$ with low burst release. This formula had higher Venlafaxine absorption in rabbits compared to the commercial capsules(Ibrahim and Salah, 2016).

\section{Materials and Methods:-}

Materials:-

Venlafaxine hydrochloride was purchased from Merck pvt ltd and poly-e-caprolactone was purchased from Sigma Aldrich (Bangalore).

\section{Preparation of microspheres:- \\ Preparation of poly-e-caprolactone microspheres by two different emulsion solvent evaporation techniques: W/O/W Method:-}

Double emulsion method of microspheres preparation involves the formation of the multiple emulsions or the double emulsion of type w/o/w. The Venlafaxine hydrochloride is mixed in $2 \mathrm{ml}$ of distilled water. Simultaneously polymer poly-e-caprolactone is dispersed in Dichloromethane. Now the drug solution is mixed in the polymer solution and emulsified. The continuous phase is consisted of the polymer solution that will encapsulate the drug contained in dispersed aqueous phase. The primary emulsion will then be subjected to the homogenization or the sonication before addition to the aqueous solution of the poly vinyl alcohol (PVA) and water. This will results in the formation of a double emulsion. The emulsion will be then subjected to solvent removal by solvent evaporation(Naik et al., 2012).

\section{W/O/O Method:-}

The Venlafaxine hydrochloride is mixed in $2 \mathrm{ml}$ of distilled water. Simultaneously polymer poly-e-caprolactone is dispersed in Dichloromethane. Now the drug solution is mixed in the polymer solution and emulsified. The continuous phase is consisted of the polymer solution that will encapsulate the drug contained in dispersed aqueous phase. The primary emulsion will then be subjected sto the homogenization or the sonication before addition to the 
solution of span 80 and $0.5 \%$ w/v liquid parrafin. This will results in the formation of a double emulsion. The emulsion will be then subjected to solvent removal by solvent evaporation(Naik et al., 2012).

\section{Compatibility study of Drug:-}

\section{DSC \& FT-IR study of formulations:-}

The DSC was done to analyse physical state of drug in the microspheres. The thermograms of the microspheres with polymer were obtained at a scanning rate of $10^{\circ} \mathrm{C} / \mathrm{min}$ conducted over a temperature range of $40-350^{\circ} \mathrm{C}$.

The FTIR analysis will carried out of the prepared microsphere with FT-IR instrument (Bruker 100597, Model: Alpha, Germany). A small amount of pure drug and crushed formulation was kept on the sample holder and scanned from $4000 \mathrm{~cm}^{-1}$ to $400 \mathrm{~cm}^{-1}$ to evaluate the physical state of the drug.

\section{Evaluations of microspheres:- \\ Particle size Analysis:-}

Microsphere size was determined using an optical microscope under regular polarised light. The mean microsphere size was calculated by measuring 100 particles.

\section{Percentage Yield:-}

The percentage yield of different formulations was determined by weighing the microspheres after drying and comparing with the total amount of drug and polymer required formulating these formulations. Percentage yield was calculated as follows,

$$
\% \text { yield }=\frac{\text { weight of the microspheres }}{\text { total weight of drug and polymer }} \times 100
$$

\section{Drug entrapment Efficiency:-}

The Venlafaxine content of biodegradable microspheres will be determined for all the formulations by dissolving $10 \mathrm{mg}$ of microspheres in $200 \mathrm{~mL}$ of DCM taken in $2 \mathrm{~mL}$ tubes and vortexed for $10 \mathrm{~min}$. The ethanol (1800mL) will be added and vortexed for another $5 \mathrm{~min}$ followed centrifugation at $3000 \mathrm{rpm}$ for $10 \mathrm{~min}$ to settle down the PCL precipitated. The supernatant containing Venlafaxine is suitably diluted using ethanol and the absorbance will be measured at $370 \mathrm{~nm}$ by UV-Vis spectrophotometry and equivalent concentration was determined using the calibration curve prepared using the same proportion of solvents. The percentage (\%) drug loading (DL) and percentage (\%) entrapment efficiency (EE) of the blend microspheres will be calculated using the following formula.

$$
\% \text { Entrapment efficiency }(\mathrm{EE})=\frac{\% \text { drug loading }}{\% \text { theoretical loading }} \times 100
$$

\section{Scanning electron microscopy (SEM):-}

The shape and surface characteristics of the microspheres were observed by scanning electron microscope (SEM). The microsphere sample was thinly sprinkled onto a metal stub and vacuum coated with thin layer of gold in argon atmosphere. The SEM photomicrographs of the coated particles were obtained at $15 \mathrm{kv}$ using a ZEISS, Germany scnning electron microscope.

In -vitro release studies:-

The in vitro dissolution of the formulations were determined by employing USP type 1 rotating basket method (900 $\mathrm{ml}$ phosphate buffer of $\mathrm{pH} 1.2,100 \mathrm{rpm}, 37 \pm 0.5^{\circ} \mathrm{C}$ ). Microspheres equivalent to $100 \mathrm{mg}$ of drug will be loaded in the basket of the dissolution apparatus. $5 \mathrm{ml}$ of sample were withdrawn from the dissolution medium at suitable time intervals and the same was replaced with same phosphate buffer of $\mathrm{pH} 1.2$ to maintain sink condition. The absorbance of the filtrate was determined at wavelength $274 \mathrm{~nm}$ by using UV visible spectrophotometer against phosphate buffer of $\mathrm{pH} 1.2$ as blank and amount of drug in the filtrate will be determined from the calibration curve and cumulative percent of drug release was calculated.

\section{Kinetic evaluation of in- vitro release Data:-}

In order to study the exact mechanism of drug release from the microspheres, drug release data were analysed according to zero order, 1st order, Higuchi square root and Korsemeyer-Peppas equations. The in-vitro release data which were obtained from optimised formulation in the dissolution medium were fitted to different kinetic models. 


\section{Result and Discussion:-}

Compatibility study of Formulations:-

FTIR analyses of the drug and their physical mixtures represented in Figure 1. The characteristic peaks of Venlafaxine showed no change in its stucture after mixing with polymers which confirmed the absence of any chemical interactions between the drug and polymers. The FT-IR study of pure drug showed principal peaks at $2942.78 \mathrm{~cm}-1$ and 1470.97 appeared due to the presence of strong $\mathrm{C}-\mathrm{H}$ stretching vibration of alkane and C-H bending of alkane respectively. Peak obseved at $768.88 \mathrm{~cm}-1$ showed chrcteristic peak due to $\mathrm{C}-\mathrm{Cl}$ stretching of halogen group. $\mathrm{O}-\mathrm{H}$ streching of alcohol group was attributed to the peak appeared at $3318.48 \mathrm{~cm}-1$. While the $\mathrm{C}=\mathrm{C}$ bending vibration of alkene was confirmed at $827.34 \mathrm{~cm}-1$. The peak at 1240.05 was attributed to $\mathrm{C}-\mathrm{N}$ stretch of amine. The IR spectra of physical mixture of Drug+PVA and Drug+PCL also showed respective peaks of drug with small shifts within their concerned range with other respective peaks of PVA and PCL. This revealed the presence of drug with no interaction which proved its compatibility. The DSC thermogram of Venlafaxine alone showed a sharp endothermic peak at $215.03^{\circ} \mathrm{C}$ with a heat of fusion of $124.42 \mathrm{~J} / \mathrm{g}$ which is similar to its standard value (Chung et al., 2007). While the DSC thermogram of Drug+PVA+PCL showed three distinguished peaks of their own. Peaks at $66.24^{\circ} \mathrm{C}, 212.60^{\circ} \mathrm{C}$ and $255.62^{\circ} \mathrm{C}$ showed sharp endothermic peaks of PCL, Venlafaxine and PVA which is similar with their reference represented in Figure 2(Pawar and Dhavale, 2014).

\section{\% yield study:-}

The yield of the microspheres prepared by both the techniques was between 75 to $85 \%$. It showes that the utilised methods provide good yield of microspheres, where the w/o/w method provides marginally better yield than w/o/o method (Table 1).

\section{Particle size Determination:-}

Venlafaxine $\mathrm{HCl}$ was successfully encapsulated and the microspheres were predominantly round and smooth with a mean particle size ranging from $130-135 \mu \mathrm{m}$ in $\mathrm{w} / \mathrm{o} / \mathrm{w}$ method, while the particles are round with a mean size ranging from 120 to $124 \mu \mathrm{m}$ in the case of w/o/o method(Table 1$)$.

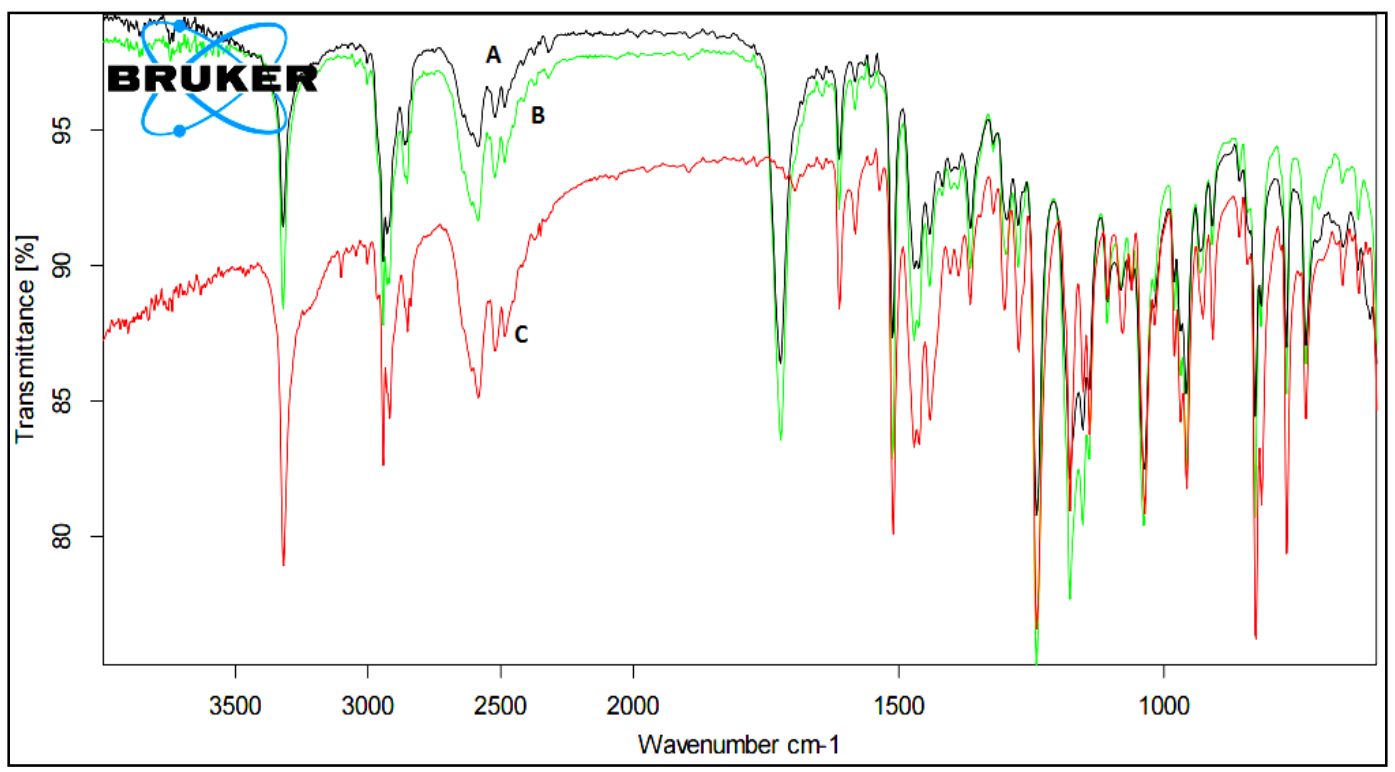

Fig. 1:- FT-IR spectra of A) VXN+PCL+PVA; B) VXN+PCL C) VENLAFAXINE. 


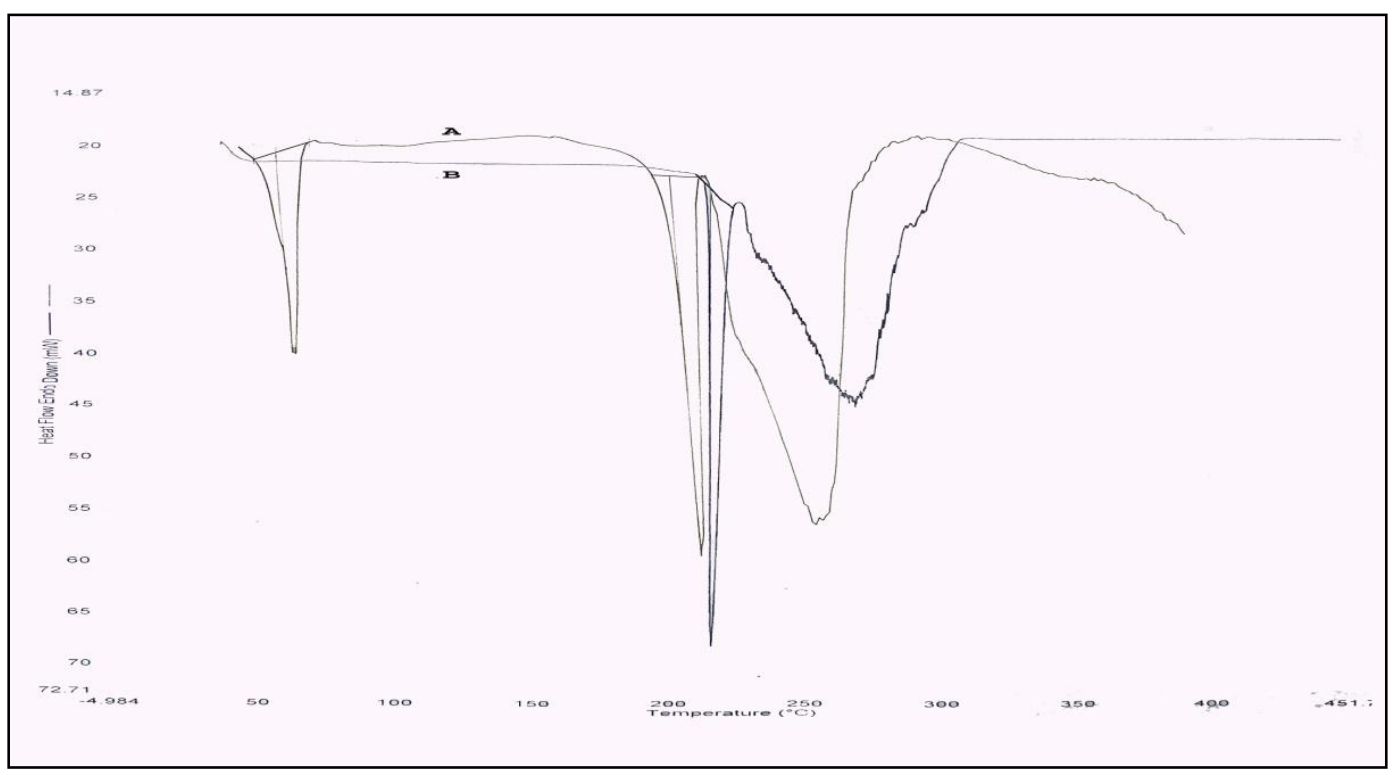

Fig. 2:- DSC thermogram of A) VENLAFAXINE and B) VENLAFAXINE+PVA+PCL

\section{Drug entrapment Efficiency:-}

The total entrapment of Venlafaxine in the microsphere prepared with w/o/o techniques was significantly greater than w/o/w technique. The high drug entrapment efficiency of microspheres can be attributed to the employment of oil as the continuous phase in preparing the emulsion (Table 1).

Table 1:- Particle size, percentage yield and drug entrapment efficiency of all formulations.

\begin{tabular}{|c|c|c|c|c|c|}
\hline $\begin{array}{l}\text { Method } \\
\text { Used }\end{array}$ & $\begin{array}{c}\text { Formulation } \\
\text { Code }\end{array}$ & $\begin{array}{c}\text { Drug/Polymer } \\
\text { Ratio }\end{array}$ & $\begin{array}{c}\text { Particle size in } \\
\text { micron }\end{array}$ & $\begin{array}{c}\% \\
\text { Yield }\end{array}$ & $\begin{array}{c}\text { Drug } \\
\text { Entrapment } \\
\text { Efficiency (\%) }\end{array}$ \\
\hline \multirow{3}{*}{ 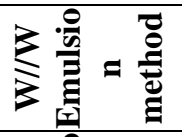 } & F 1 & $1: 1$ & $171 \pm 3.7$ & $61.4 \pm 0.35$ & $74.51 \pm 0.6$ \\
\hline & F 2 & $1: 2$ & $113 \pm 2.5$ & $85.3 \pm 0.68$ & $80.35 \pm 0.93$ \\
\hline & F 3 & $1: 3$ & $102 \pm 2.1$ & $92.21 \pm 1.57$ & $76.13 \pm 1.7$ \\
\hline \multirow{3}{*}{ 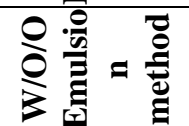 } & F 4 & $1: 1$ & $134 \pm 1.7$ & $71.14 \pm 2.3$ & $75.18 \pm 0.5$ \\
\hline & F 5 & $1: 2$ & $127 \pm 2.3$ & $89.15 \pm 1.9$ & $90.21 \pm 0.82$ \\
\hline & F 6 & $1: 3$ & $120 \pm 1.4$ & $91.33 \pm 0.61$ & $85.53 \pm 1.4$ \\
\hline
\end{tabular}

All the values are expressed in mean $\pm \mathrm{SD}(\mathrm{n}=3)$

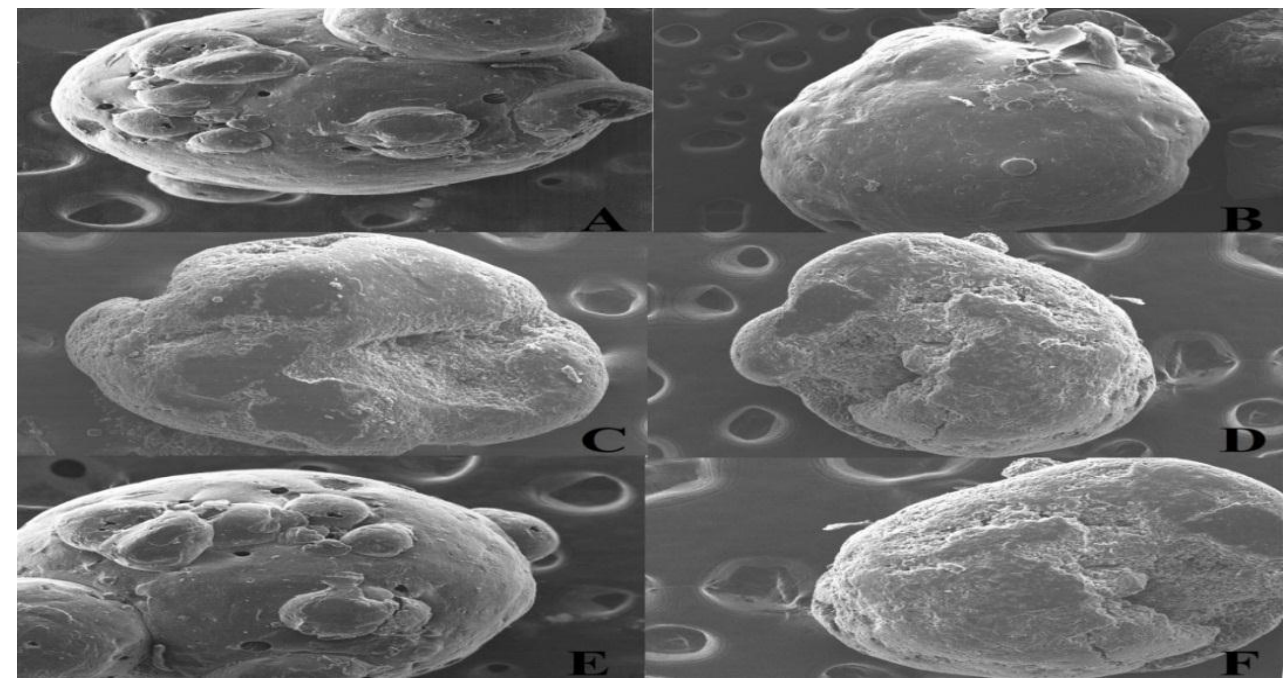

Fig 3:- SEM photographs of A)F 1, B)F 2, C)F 3, D)F 4, E)F 5, F)6 


\section{Scanning electron microscopy (SEM):-}

Scanning electron microscopy of drug loaded microspheres (Figure 3) revealed that microspheres possess almost smooth surface and spherical shape while cracks were also present on the surface of microspheres and clumps were also present .SEM photographs revealed the absence of crystals of drug on the surface of the microspheres, indicating uniform distribution of drug within these microspheres.

\section{In-vitro Release Study:-}

Release studies reveals that the release behavior of drug was governed by the microstructure of PCL microparticles, suggesting that the environment for diffusion changes according to processing conditions such as polymer solution concentration, thermal history, and polymer molecular weight. The release profiles of VLF from the microspheres prepared using o/o/o method, with organic solvent blend (dichloromethane: ethanol), showed a burst release of about 60 to $90 \%$ after first one hour. W/O/W method showed a burst release of about 35 to $40 \%$ after first one hour. The burst release is directly proportional to their total entrapment values. There was a gradual increase in the drug release till the $6 \mathrm{hr}$ in all the batches and after wards the release was very slow. About $60 \%$ of the VLF was released in 12 hours. The \% cumulative drug release from all formulations is represented in Figure 4.

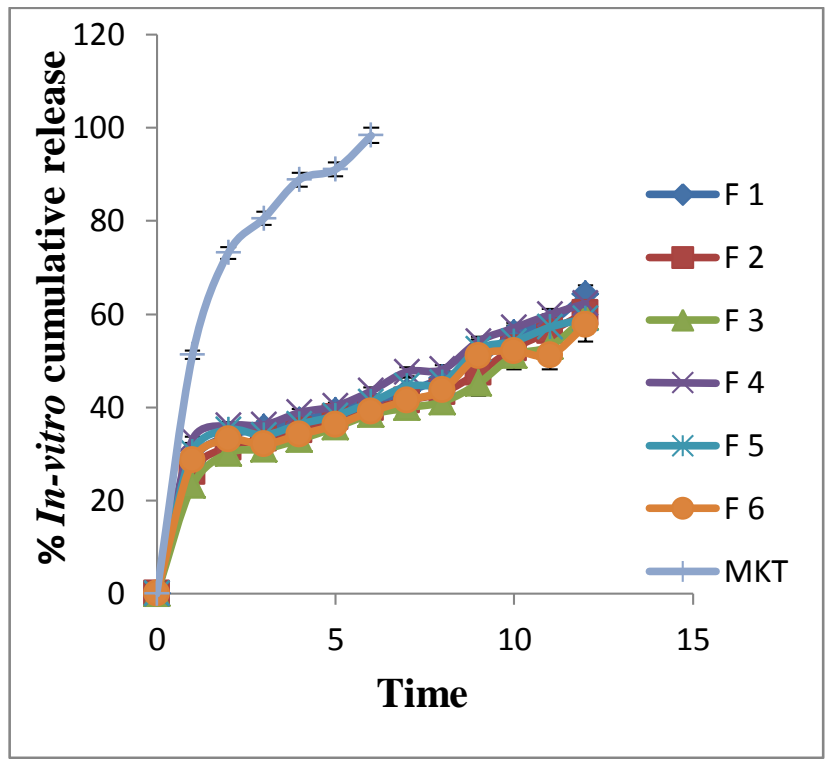

Figure 4:- Cumulative release of Venlafexin from different formulations.

\section{Kinetic evaluation of in vitro release Data:-}

The in vitro release kinetics of the Venlafaxine loaded microspheres was poltted in various kinetic models and represented in Table 2. The release constants for formulations F1-F6 were calculated from the slope of the appropriate plots, and regression coefficient $\left(\mathrm{r}^{2}\right)$ by linear regression analysis. The zero-order release values for formulations were $0.294-0.535$ and $0.598-0.724$ for first order (Table 3). The F1-F6 formulations release regression values $\left(\mathrm{r}^{2}\right)$ were best fitted with the Higuchi plot with a regression range of $0.881-0.938$ rather than first and zero orders (Table 3). But the F4, F5 and F6 showed a similar type of regression range. Thus the drug release of Venlafaxine was proportional to the square root of time, indicating diffusion controlled-release mechanism for all the formulations. While the marketted formulation (F7) showed first order release pattern for Venlafaxine. Further study on Korsmeyer-Peppas model revealed that the exponent values were found to lie within a range of 0.948 and 0.955 and the release exponent $(\mathrm{n})$ values were found in between 0.31-0.39 $(\mathrm{n}<0.5)$ indicating a Fickian type of release mechansim. 
Table 2:- Modelling and release kinetics of irinotecan from different gel formulations

\begin{tabular}{|c|c|c|c|c|c|c|c|c|}
\hline Model & Parameter & F 1 & F 2 & F 3 & F 4 & F 5 & F 6 & F 7 \\
\hline \multirow{2}{*}{ Zero order } & $\mathrm{R}_{\text {adjusted }}^{2}$ & 0.4465 & 0.4714 & 0.5350 & 0.2946 & 0.3186 & 0.3429 & 0.5514 \\
\cline { 2 - 9 } & $\mathrm{K}_{0}$ & 5.980 & 5.678 & 5.451 & 6.177 & 5.868 & 5.570 & 20.224 \\
\hline \multirow{2}{*}{ First order } & $\mathrm{R}_{\text {adjusted }}^{2}$ & 0.6815 & 0.6914 & 0.7249 & 0.6020 & 0.5988 & 0.5999 & 0.9896 \\
\cline { 2 - 9 } & $\mathrm{K}_{1}$ & 0.090 & 0.083 & 0.078 & 0.096 & 0.088 & 0.082 & 0.624 \\
\hline \multirow{2}{*}{ Higuchi } & $\mathrm{R}^{2}$ adjusted & 0.9144 & 0.9265 & 0.9384 & 0.8819 & 0.8857 & 0.8902 & 0.9522 \\
\cline { 2 - 9 } & $\mathrm{K}_{\mathrm{H}}$ & 17.796 & 16.887 & 16.174 & 18.474 & 17.537 & 16.633 & 43.650 \\
\hline \multirow{2}{*}{$\begin{array}{c}\text { Korsmeyer- } \\
\text { Peppas }\end{array}$} & $\mathrm{R}_{\text {adjusted }}$ & 0.9482 & 0.9559 & 0.9552 & 0.9551 & 0.9514 & 0.9485 & 0.9926 \\
\cline { 2 - 8 } & $\mathrm{K}_{\mathrm{KP}}$ & 23.689 & 22.072 & 20.107 & 26.992 & 25.268 & 23.604 & 55.291 \\
\cline { 2 - 9 } & $\mathrm{n}$ & 0.358 & 0.367 & 0.392 & 0.311 & 0.318 & 0.325 & 0.327 \\
\hline
\end{tabular}

\section{Conclusion:-}

On account of the present study, it can be concluded that Venlafaxine was successfully microencapsulated into poly$\varepsilon$-caprolactone micropsheres by both the double emulsification methods. Out of these two different emulsion methods w/o/o gives better entrapment efficiency and controlled release characteristics as compared to w/o/w method. PCL appeared to be promising carrier for Venlafaxine $\mathrm{HCl}$ controlled release formulations, because of its biodegradability and biocompatibility. Also the prepared Venlafaxine $\mathrm{HCl}$ loaded poly-e-caprolactone microspheres released the drug over extended period of time which strengthen its approach as a possible candidate for controlled drug delivery.

\section{Acknowledgement:-}

The authors would like to thank the Girijananda Chowdhury Institute of Pharmaceutical Science for providing all the facilities for the study.

Author contribution:-

All the authors have contributed to the experimental work and in preparation of the article.

\section{Declaration:-}

All the authors declared no conflict of interest.

\section{References:-}

1. Chung, Y.S., Kang, S.I., Kwon, O.W., Lee, S.G., Lee, Y.R., Min, B.G., Han, S.S., Noh, S.K., Lyoo, W.S., 2007. Preparation of hydroxyapatite/poly(vinyl alcohol) composite film with uniformly dispersed hydroxyapatite particles using citric acid. J. Appl. Polym. Sci. 104, 3240-3244. doi:10.1002/app.25949

2. Di Silvio, L., Bonfield, W., 1999. Biodegradable drug delivery system for the treatment of bone infection and repair. J. Mater. Sci. Mater. Med. 10, 653-658.

3. https://dailymed.nlm.nih.gov/dailymed/archives/fdaDrugInfo.cfm?archiveid=9595, 12/2008. EFFEXOR - venlafaxine hydrochloride tablet, Wyeth Pharmaceuticals Inc.

4. Hombreiro Pérez, M., Zinutti, C., Lamprecht, A., Ubrich, N., Astier, A., Hoffman, M., Bodmeier, R., Maincent, P., 2000. The preparation and evaluation of poly( $\epsilon$-caprolactone) microparticles containing both a lipophilic and a hydrophilic drug. J. Control. Release 65, 429-438. doi:10.1016/S0168-3659(99)00253-9

5. Ibrahim, H.K., Salah, S., 2016. Formulation of venlafaxine for once daily administration using polymeric material hybrids. J. Microencapsul. 33, 299-306. doi:10.1080/02652048.2016.1178351

6. Lionzo, M.I.Z., Ré, M.I., Guterres, S.S., Pohlmann, A.R., 2007. Microparticles prepared with poly(hydroxybutyrateco-hydroxyvalerate) and poly( $\varepsilon$-caprolactone) blends to control the release of a drug model. J. Microencapsul. 24, 175-186. doi:10.1080/02652040701233556

7. Naik, J.B., Lokhande, A.B., And, S.M., Kulkarni, R.D., 2012. Development of Sustained Release Micro / Nano Particles Using Different Solvent Emulsification Techniques : a Review. Int. J. Pharma Bio Sci. 3, 573-590.

8. Paul, W., Sharma, C.P., 2003. Ceramic drug delivery: a perspective. J. Biomater. Appl. 17, $253-264$. doi:10.1177/0885328203017004001

9. Pawar, H.A., Dhavale, R., 2014. Development and evaluation of gastroretentive floating tablets of an antidepressant drug by thermoplastic granulation technique. Beni-Suef Univ. J. Basic Appl. Sci. 3, $122-132$. doi:10.1016/j.bjbas.2014.05.005

10. Raval, J.P., Naik, D.R., Amin, K.A., Patel, P.S., 2014. Controlled-release and antibacterial studies of doxycyclineloaded poly(E-caprolactone) microspheres. J. Saudi Chem. Soc. 18, 566-573. doi:10.1016/j.jscs.2011.11.004 